\title{
O ESTAR-JUNTO NO COTIDIANO DA FORMAÇÃO DE PROFESSORES DE BIOLOGIA: SOBRE POSSÍVEIS RELAÇÕES ENTRE AMBIÊNCIA E ACONTECIMENTOS CURRICULARES
}

\section{THE BEING -TOGETHER IN DAILY LIFE OF BIOLOGY TEACHER TRAINING: ABOUT POSSIBLE RELATIONSHIP BETWEEN ENVIRONMENT AND CURRICULUM EVENTS}

\author{
PIMENTEL JUNIOR, Clívio \\ clivio.pimentel@gmail.com \\ UFBA - Universidade Federal da Bahia
}

\begin{abstract}
RESUMO Partindo de um mergulho interpretativo nos cotidianos escolar e universitário vivenciados por uma turma de licenciandos em Ciências Biológicas, o texto tem como objetivo problematizar as maneiras de estar-junto identificadas em um grupo e suas ressonâncias nas práticas pedagógicas curriculares. $O$ trabalho configura-se em uma pesquisa no/do cotidiano com aporte de técnicas interpretativas e etnográficas. Episódios interpretativos são construídos como modo de apreensão dos fenômenos cotidianos vivenciados em campo. As constatações construídas provocam a pensar em como a força da ambiência cotidiana pode ser estruturante dos modos como os licenciandos pensam e agem em sala de aula, determinando suas tomadas de decisão em contextos formais de prática de ensino.
\end{abstract}

PALAVRAS-CHAVE: Cotidiano. Currículo. Estética. Formação de professores. Pósmodernidade.

ABSTRACT Departing from an interpretative dip in schools and universities everyday life experienced by undergraduates in Biology, this paper aims to problematize the ways of being-together identified in a group and its resonance in curriculum pedagogical practices. The work sets up in a research on/with the everyday, input of interpretative and ethnographic techniques. Interpretive episodes are built as apprehension mode of everyday phenomena experienced in the field. The built findings provoke to think about how everyday ambience force can be structuring the ways in which student teachers think and act in the classroom, determining their decision making in teaching practice formal contexts.

KEY WORDS: Aesthetics. Curriculum. Everyday life. Teacher Training. Postmodernity. 
Atos de Pesquisa em Educação - ISSN 1809-0354

Blumenau - vol. 11, n. 2, p.590-610 ago./nov. 2016

DOI: http://dx.doi.org/10.7867/1809-0354.2016v11n2p590-610

A história inventada ${ }^{1}$ neste trabalho expressa o grau de identificação que tenho estabelecido com os espaçostempos (ALVES, 2001) vividos por mim. Uma história que expressa ressonâncias de como estes espaçostempos vividos/lidos/sentidos/ouvidos (OLIVEIRA, 2007) têm me formado e agenciado maneiras de escrever, falar e agir na pesquisa em educação. Convido-os ${ }^{2}$ a compartilhar e entender o giro compreensivo (MAFFESOLI, 2008) das concepções de currículo e formação trabalhadas neste texto não como algo que dita, do alto e de modo soberbo, o que esta deve ser para trilhar o caminho certo. Indo na contramão desta gana de querer controlar e concluir a efervescência da vida (MAFFESOLI, 2008), convido a pensar em uma concepção de formação que assume aquilo que expresso como, em alguma medida, ressonância da aura estética (MAFFESOLI, 2005) que compartilho em cada espaçotempo educativo que ingresso ao longo do percurso formativo. Uma concepção a qual toda itinerância existencial é levada em conta, todos os passos dados são preservados - incluindo aí os supostos desvios através da variedade de referências invocadas, conscientemente ou não, no relacionamento com o mundo. Ideias inspiradas, sobretudo, nos estudos de Alves (2001), Carvalho (2001), Certeau (2009) e Maffesoli (1996, 2005, 2008). As intenções epistemológicas e ontológicas desse giro compreensivo na investigação da problemática que se anuncia a seguir estão bem caracterizadas pelas palavras filosófico-poéticas de Maffesoli:

Isto é, aquilo que introduz a um pensamento acariciante, que pouco se importa com a ilusão da verdade, que não propõe um sentido definitivo das coisas e das pessoas, mas que se empenha sempre em manter-se a caminho. No sentido estrito, trata-se de um "método" erótico, enamorado pela vida, e que se empenha em mostrar sua fecundidade. (MAFFESOLI, 2008, p. 113-114. Grifo meu)

\footnotetext{
${ }^{1} A$ noção de invenção à qual recorro, e que tem apresentado forte potencial heurístico em investigações do cotidiano (CARVALHO, 2001), faz referência aos estudos de Maffesoli (2005, p.13), para quem "inventa-se um mundo cada vez que se escreve. Trata-se, na verdade, indo ao encontro da etimologia, invenire, de fazer vir à luz do dia o que já existe, vivido amplamente na experiência cotidiana, embora os hábitos de pensar impeçam-nos de vê-lo."

2 Tenho aprendido com Maffesoli (1996, 2005) e com Garcia (2007), a pensar numa estética do convite que é dotado de imprevisibilidade, risco e incerteza. Tenho considerado que o convite "é massa pura de devir, de atualização, de certa virtualidade imanente. Sendo assim, ele move-mente: é puro movimento." (GARCIA, 2007, p. 13). Apoiado em Garcia (2007), tenho defendido que o convite promove encontros e provoca-ações a partir do grau de abertura que disponibilizamos para que as alteridades se encontrem e se re-conheçam como perspectivas.
} 
Atos de Pesquisa em Educação - ISSN 1809-0354

Blumenau - vol. 11, n. 2, p.590-610 ago./nov. 2016

DOI: http://dx.doi.org/10.7867/1809-0354.2016v11n2p590-610

Há nomadismo no ar! Talvez seja o manter-se a caminho a característica mais marcante deste giro compreensivo quando se está pesquisando o cotidiano em suas inter-relações com o campo do currículo e das redes de saberes da/na formação de professores. O desafio é manter-se em permanente estado de busca, sem a petrificação categórica dos enigmas investigados. Apresento neste trabalho algumas constatações construídas, com rigorosas revisões, numa pesquisa de mestrado defendida no Programa de Pós-graduação em Educação da Faculdade de Educação, Universidade Federal da Bahia. Os posicionamentos defendidos aqui emergiram a partir das discussões que vimos tendo semanalmente em reuniões do nosso grupo de pesquisa cujo foco de investigação faz referência ao potencial formativo dos cotidianos. Temos defendido que é nos cotidianos vividos que formamos e somos formados por redes de saberes, fazeres e dizeres estabelecidas dentro e fora das escolas que, por sua vez, condicionam nossas maneiras de estar no mundo. (ALVES, 2001, 2003; CARVALHO, 2001; OLIVEIRA \& ALVES, 2001, 2006; OLIVEIRA, 2001, 2007). Particularmente nesses estudos, minha intenção tem sido avançar na compreensão de como estas redes formativas condicionam maneiras de estar-junto nas tessituras de práticas pedagógicas curriculares no cotidiano escolar. Meu interesse tem sido avançar na compreensão de como os espaçostempos vividos se enredam às dinâmicas com-partilhadas ${ }^{3}$ de significação e tessitura curricular nos cotidianos escolares. De modo mais específico, focalizo as tessituras produzidas por um grupo de licenciandos em Biologia, no momento do estágio supervisionado, mostrando como tenho operado na compreensão de tais interesses. Para tanto, estruturei este trabalho da seguinte forma: parto de uma caracterização das pesquisas do/no cotidiano em consonância com os referentes entre os quais tenho caminhado, e apresento, em seguida, as ações metodológicas da investigação. Por fim, apresento o episódio interpretativo construído e debato algumas questões levantadas pelo mesmo, com vistas a defender que a força da ambiência nos espaçostempos vividos

\footnotetext{
${ }^{3} \mathrm{O}$ sentido de com-partilhado que adoto está filiado às teorizações de Maffesoli (1996). Interessa-me, coadunado a esta perspectiva, investigar os momentos de atração estética que fundam agregações voláteis que nascem com a própria interação que se estabelece em dinâmicas formativas contextualizadas, no tempo e no espaço, sem determinações a priori.
} 
Atos de Pesquisa em Educação - ISSN 1809-0354

Blumenau - vol. 11, n. 2, p.590-610 ago./nov. 2016

DOI: http://dx.doi.org/10.7867/1809-0354.2016v11n2p590-610

tem potencial estruturante das significações curriculares, com implicações didáticas e pedagógicas para o ensino de Biologia.

\section{AS PESQUISAS DO/NO COTIDIANO E A PÓS-MODERNIDADE}

Em meus estudos, tenho defendido alguns posicionamentos que fazem referência às pesquisas dos/nos cotidianos, perspectivadas pelo movimento de pensamento pós-moderno. O primeiro deles diz respeito à metáfora das redes (ALVES, 2001; OLIVEIRA, 2007) e os modos pelos quais tenho operado com ela na compreensão dos diversos saberes que formamos e pelos quais somos formados ao estar no mundo. A metáfora das redes implica em reconhecer a multiplicidade de saberes, conhecimentos e culturas que, irremediavelmente, compõe tanto a nós como aos cotidianos vividos. Não se trata simplesmente de uma multiplicidade de saberes que convivem pacífica e idealmente, pois, muitas vezes, são conflituosos e disputam hegemonia entre si. Isto nos coloca diante do desafio de assumir a temporalidade da harmonia conflituosa (MAFFESOLI, 2005) entre a diversidade desses saberes como possíveis maneiras de existir. Em Santos (2007), encontramos ideias que entram em ressonância com esta forma de pensar as formas de sociabilidade a partir das noções de ecologia de temporalidades e ecologia de saberes. São noções que avançam numa crítica radical às pretensões do cientificismo, e sua gana soberba de tentar promover uma assepsia (MAFEESOLI, 2005) do corpo social, mediante uma faxina lógica (CERTEAU, 2009), em busca do controle do ser em seu devir existencial.

$\mathrm{Da}$ assunção desta metáfora, decorre que investigar essas redes e temporalidades requer beber em todas as fontes (ALVES, 2001) na tentativa de compreender o que nela se produz e de que modo se é produzido. As noções de identificações e máscaras ${ }^{4}$ - persona, pessoa - que venho desenvolvendo na compreensão da história que conto com essas redes perseguem o que Maffesoli

\footnotetext{
${ }^{4}$ A noção de máscaras que tomo de Maffesoli para compreender a multiplicidade de formas de expressão dos saberes e das culturas das pessoas formados nas redes de saberes, fazeres e dizeres que tecem e pelas quais são tecidos nos diversos espaçostempos cotidianos vivenciados não comporta a ideia de substituição ou superação de uma por outra. Esta noção abarca a possibilidade da coexistência de elementos contrários, opostos, sem ultrapassar essas contradições em uma síntese. A noção de máscaras, portanto, reforça a não-linearidade neste processo de vestimenta de máscaras, alías, reforça o caráter horizontal e deslocado dessa formação estética: é incompatível pensar numa trajetória de máscaras se sucedendo linearmente, dado que a própria busca da máscara, da identidade una e definitiva do sujeito não acontece de acordo com essa perspectiva.
} 
Atos de Pesquisa em Educação - ISSN 1809-0354

Blumenau - vol. 11, n. 2, p.590-610 ago./nov. 2016

DOI: http://dx.doi.org/10.7867/1809-0354.2016v11n2p590-610

defende como sendo a saturação da lógica do sujeito moderno, senhor de si, dotado de plena consciência e razão sobre suas tomadas de decisões cotidianas (MAFFESOLI, 1996). Ao lado disso, tenho defendido que as noções aqui trabalhadas abrem a possibilidade de pensar numa formação estética e social nos espaçostempos cotidianos habitados que é fruto dos valores e sentidos com-partilhados na formação. Trata-se de compreender como esses sentidos se expressam, também, por meio de situações aparentemente anódinas nos acontecimentos e, dentre eles, os curriculares, o que exige do pesquisador esquemas de operação flexíveis, um sentir o mundo de modo plural.

Outro posicionamento característico das pesquisas do/no cotidiano assumido neste trabalho diz respeito à ideia de que falar do cotidiano é operar por meio de contações de histórias (CARVALHO, 2001). Isto é, significa assumir que "sou um narrador praticante ao traçar/trançar as redes dos múltiplos relatos que chegaram/chegam até mim, neles inserindo, sempre, o fio do meu modo de contar." (ALVES, 2001, p.32-33). Nessa perspectiva, falar do/no cotidiano neste trabalho significa reconhecer que, mesmo operando por meio de um afastamento reflexivo, convém aceitar que não estamos completamente separados. Isto é, ao passo que contamos, somos também contados por essas histórias inventadas, o que implica aceitar que toda descrição é também um ato de criação. Partindo dessas perspectivas libertárias, tenho defendido que estar no e pesquisar o cotidiano é, também, relativizar valores e categorias outrora tidos como suficientes, é vislumbrar o desmanchamento de categorias peremptórias e perceber o aspecto gelatinoso e vacilante das fronteiras que supostamente encerram conhecimentos. Enfim, é festejar o surgimento de um ethos diferente de pesquisa dos modos de sociabilidade, com seus altos e baixos, grandezas e declínios, em suma, com suas histórias e não apenas com uma História:

A aplicação dos instrumentos de análise da retórica à historiografia mostrou que, no fundo, a imagem da história que nós temos é toda ela condicionada pelas regras de um gênero literário; em suma, que a história é muito mais uma "estória", um relato, do que realmente se está disposto a admitir. (VATTIMO, 2007, p. XIV)

Carvalho (2001), por exemplo, provoca a discussão acerca da distinção entre história e estória como forma de problematizar a pretensão e o tratamento peremptório e cientificista de historiadores que almejam, através de suas narrativas, atingir a 
Atos de Pesquisa em Educação - ISSN 1809-0354

Blumenau - vol. 11, n. 2, p.590-610 ago./nov. 2016

DOI: http://dx.doi.org/10.7867/1809-0354.2016v11n2p590-610

verdade una da História. Inspirada nos estudos de Vattimo (2007), convida-nos a interrogar a lógica representacionista da História Universal e sua suposta aproximação fiel da realidade:

Ao longo da história humana, com muita freqüência, as mais diversas correntes do pensamento teórico vêm almejando atingir esse modo correto de compreender o passado assim como o presente. São as tentativas de busca/encontro da verdade. Uma história, portanto, pretensamente unitária, que, tanto na vertente da neutralidade positivista como naquela de valorização das estruturas sociais e políticas dos historiadores radicais ou críticos, tenta negar, de uma ou outra forma, o vínculo entre história e estória. Mas, haverá um modo correto de compreender o passado e o presente? É o que, ao longo das últimas décadas, com cada vez mais intensidade, vem sendo perguntado. É a própria história (aqui no sentido concreto dos fluxos objetivos da vida prático-simbólica), que, no seu plural acontecer cotidiano, vai apontando a impossibilidade da não existência de vínculos entre história e estória. Uma história que vai deixando de ser História para ser histórias. (CARVALHO, 2001, p. 7)

É nisso que a pós-modernidade inaugura uma forma de solidariedade social que não é mais racionalmente definida, mas que, ao contrário, se elabora a partir de um processo complexo feito de atrações, repulsões, emoções e paixões. [...] Assim, a estética marginalizada na perspectiva finalizada da história pode se tornar central na do destino (a pós-história). Naquela, cada coisa só vale na medida em que se inscreve numa mecânica evolutiva, o drama no seu sentido etimológico; nesta cada coisa, sendo o elemento significante de uma organicidade, vale por si mesma: dai o trágico que se vive no presente. (MAFFESOLI, 1996, p.15-40)

Apoiado em Carvalho (2001), Maffesoli (1996) e Vattimo (2007), construo nesse trabalho uma pequena história referente a acontecimentos aparentemente anódinos que deixam ver sua profundidade nos modos de significar e tecer o ensino de Biologia nos cotidianos escolares. É justamente nesse sentido que a história inventada por mim neste trabalho passa a ter como objetivo a problematização ${ }^{5}$ das relações gestadas entre as redes de saberes, fazeres e dizeres mobilizados por um grupo de licenciandos em Ciências Biológicas com vistas a entender como estas condicionam maneiras de estar-junto (MAFFESOLI, 1996, 2005, 2008) no fazer curricular. Essas redes são entendidas como formadas em e formadoras de valores, pensamentos e atitudes praticadaspensadas (OLIVEIRA, 2007) na ambiência formativa vivida pelos

\footnotetext{
5 Em Foucault (2006, p.233-242) problematização é "o conjunto das práticas discursivas e não discursivas que faz alguma coisa entrar no jogo do verdadeiro e do falso e o constitui como objeto para o pensamento." Neste trabalho, cabe destacar que a prática da problematização foge à busca de soluções metódicas e peremptórias. Nesse sentido, não penso em solucionar, de modo definitivo, a problemática, mas operar um "afastamento" no sentido de exercitar o pensamento sobre o problema investigado, dando a pensar no mesmo de modo a ampliar as discussões propostas.
} 
Atos de Pesquisa em Educação - ISSN 1809-0354

Blumenau - vol. 11, n. 2, p.590-610 ago./nov. 2016

DOI: http://dx.doi.org/10.7867/1809-0354.2016v11n2p590-610

mais diversos espaçostempos, dentre eles, a Universidade. As maneiras de estarjunto, por sua vez, são tomadas como dinâmicas de socialização estruturantes de significações e tessituras curriculares vividas nos cotidianos escolares e universitários pelo grupo. Trata-se de dinâmicas que condicionam os valores e atitudes tomadas em contextos formais de ensino, participando, desta forma, implícita e explicitamente, do fazer curricular e impulsionando estratégias educacionais, neste caso, de ensino de Biologia. Assim, neste trabalho são narrados pequenos acontecimentos, mas nem por isso menos importantes, da formação de um grupo de licenciandos e que dão a pensar sobre as relações entre currículo, conhecimentos, saberes e fazeres na formação de professores. Tais acontecimentos são compreendidos em sinergia com a força da ambiência vivida nos cotidianos da Universidade, que não estão restritos aos campos empíricos observados e descritos.

\section{SOBRE PERSPECTIVAS METODOLÓGICAS NA COMPREENSÃO DAS "MANEIRAS DE ESTAR-JUNTO"}

Em minhas investigações do/no cotidiano, tenho operado a partir dos registros pós-modernos expressos nas sociologias do cotidiano de Maffesoli $(1996,2005,2008)$ e Certeau (2009a; 2009b), como forma de pensar sobre a dimensão ética e estética dos saberes e fazeres implicados nas maneiras de estar-junto. Trata-se de pensar nos valores e atitudes que têm poder de gerar agregações, de fazer as práticaspensamentos de um grupo girar em torno delas. Em paralelo, tenho defendido que pensar as maneiras de estar-junto não pode passar ao largo da noção de ambiência: "nada escapa à ambiência de uma época, nem mesmo os que creem ser completamente independentes." (MAFFESOLI, 2005, p.105). Partindo dessas noções, intentei, neste trabalho, descrever atitudes e valores praticadospensados, porque vividos, nos ambientes curriculares nos quais os licenciandos ingressam ao longo do percurso formativo. Trata-se de práticaspensamentos que deixam ver a dimensão estética e formativa da ambiência como força estruturante das redes de saberes que marcam as significações curriculares nos cotidianos observados e vividos. Defendo, portanto, que a força da ambiência englobante condiciona profundamente as atitudes individuais e as maneiras de pensar e agir dos praticantes de um grupo, participando também de suas tessituras curriculares nos cotidianos. O desafio está em 
Atos de Pesquisa em Educação - ISSN 1809-0354

Blumenau - vol. 11, n. 2, p.590-610 ago./nov. 2016

DOI: http://dx.doi.org/10.7867/1809-0354.2016v11n2p590-610

compreender como as práticaspensamentos expressos pelos licenciandos fornecem pistas sobre um determinado ambiente formativo e quais suas ressonâncias no espaço escolar. Trata-se, notadamente, da compreensão de um ethos que convém abordar de modo compreensivo, atento e interessado:

Os relatos de que se compõem está obra pretendem narrar práticas comuns. Introduzi-las com as experiências particulares, as freqüentações, as solidariedades até as lutas que organizam o espaço onde essas narrações vão abrindo um caminho, significará delimitar um campo. [...] Para ler e escrever a cultura ordinária, é mister reaprender operações comuns. (CERTEAU, 2009, p.35)

Aceitar como dignas de interesse, de análise e de registro aquelas práticas ordinárias consideradas insignificantes. Aprender a olhar esses modos de fazer, fugidios e modestos, que muitas vezes são o único lugar de inventividade possível do sujeito: invenções precárias sem nada capaz de consolidá-las, sem língua que possa articulá-las, sem reconhecimento para enaltecê-las; [...] inscritas na rede das determinações concretas. (GIARD, 2009, p.217)

Atento às palavras de Certeau (2009) parti para a descrição de práticas de significações curriculares comuns, pautadas em valores tradicionalmente compartilhados e tidos como desejáveis nos espaços formativos vividos. Nesse sentido, foi possível perseguir um dos enigmas construídos neste trabalho: como se caracterizam as maneiras de estar-junto, analisadas através da formação de professores em Ciências Biológicas, e quais suas ressonâncias no currículo escolar? Está em foco, portanto, nesse trabalho, o modo como os licenciandos dão forma às suas práticas de ensino a partir do que vivenciam nos cotidianos formativos. Disto decorre estar atento aos valores de inter-esse expressos no grupo, e não dos indivíduos em si:

A forma é apenas uma tipificação elaborada a partir de dados observáveis, feitos à base de descrições sem que se trate de suspeitar, criticar o que é observado ou descrito. [...] Ela pode variar na sua intenção ou aplicação; em compensação ela não varia na sua função agregativa. [...] A forma justifica, ao mesmo tempo, o geral e o particular, o "universal concreto". O universal, no caso, sendo o ambiente geral no qual nos banhamos, enquanto massa, 0 particular, ou o concreto, sendo a maneira pela qual um grupo vai se aninhar nesse ambiente geral, a maneira pela qual ele vai se apropriar de um valor geral ou de um conjunto de valores. (MAFFESOLI, 1996, p.143-146)

O exame dessas práticas não implica um regresso aos indivíduos. $\mathrm{O}$ atomismo social que, durante três séculos, serviu de postulado histórico para uma análise da sociedade supõe uma unidade elementar, o indivíduo, a partir do qual seriam compostos os grupos e à qual sempre seria possível reduzi- 
Atos de Pesquisa em Educação - ISSN 1809-0354

Blumenau - vol. 11, n. 2, p.590-610 ago./nov. 2016

DOI: http://dx.doi.org/10.7867/1809-0354.2016v11n2p590-610

los. [...] De um lado, a análise mostra antes que a relação (sempre social) determina seus termos, e não o inverso, e que cada individualidade é o lugar onde atua uma pluralidade incoerente (e muitas vezes contraditória) de suas determinações relacionais. De outro lado, e sobretudo, a questão tratada se refere a modos de operação ou esquemas de ação e não diretamente ao sujeito que é seu autor ou seu veículo. (CERTEAU, 2009, p.37)

No que diz respeito à dimensão formante do cotidiano, tento compreendê-la a partir das diversas referências pensadas, mobilizadas e praticadas, porque vividas, nos espaçostempos cotidianos da formação. Há viscosidade no ar! Algumas técnicas de pesquisa foram necessárias na realização desta empreitada complexa: a técnica de observação participante interpretativa proposta por Erickson (1985) mostrou-se teoricamente compatível aos propósitos do trabalho. Na vertente defendida por ele, as observações participantes e as pesquisas interpretativas estudam os sentidos atribuídos pelas pessoas aos fatos que acontecem cotidianamente tanto numa escala face-to-face (ERICKSON, 1985) quanto numa macroescala, ou seja, os eventos que ocorrem no entorno do contexto imediato das ações observadas, as ocasiões e circunstâncias. De modo ampliado, a assunção desta técnica no trabalho teve como intento maior apreender o modo como os eventos de significação curricular observados estavam aderidos aos espaçostempos vividos. No que diz respeito ao campo empírico, considerei que o lócus mais apropriado seria o percurso formativo que vivi - o curso de Licenciatura em Ciências Biológicas da Universidade Federal da Bahia (UFBA) -, sobretudo, no momento final do curso - o do estágio supervisionado -, o qual deu a possibilidade de (re)viver tanto a formação no contexto universitário, quanto no contexto inicial da prática de ensino. O critério de escolha deste campo se deu justamente pelo desafio assumido: para compreender estas maneiras de estarjunto, considerei necessário ter vivido essas práticaspensamentos e valores compartilhados, como forma de investigar de modo implicado os mesmos. Isso tornou a pesquisa de campo, em alguma medida, uma (re)visita a espaçostempos outrora vividos. Dois foram os campos principais de observação: as aulas da disciplina Metodologia e Prática do Ensino de Biologia II, ministradas na FACED/UFBA, bem como em uma das escolas em que os estudantes realizaram o estágio supervisionado, o Instituto Federal de Educação, Ciência e Tecnologia da Bahia (IFBA). Na Universidade, as aulas foram acompanhadas durante o período de um semestre. Já no campo de estágio escolar, em decorrência do próprio período de intervenção, as 
Atos de Pesquisa em Educação - ISSN 1809-0354

Blumenau - vol. 11, n. 2, p.590-610 ago./nov. 2016

DOI: http://dx.doi.org/10.7867/1809-0354.2016v11n2p590-610

aulas foram acompanhadas durante um bimestre, por meio de observações diretas das aulas de um dos licenciandos do curso. Os registros das narrativas e depoimentos orais que foram trazidos à cena nesses momentos de observação foram realizados em diário de campo, prática investigativa tributária dos métodos etnográficos e que, neste trabalho, foi realizada a partir das teorizações de Pimentel (2009) .

Apresento, a seguir, os dados na forma de episódios que denominei Cenas e Máscaras do/no Cotidiano, tecidos nos/com os cotidianos investigados. O critério de seleção, na construção dos episódios, tomou como referência as situações que provocavam com-partilhamento de valores e atitudes, formação de núcleos, maneiras de estar-junto. São descrições de cenas e posicionamentos que, apesar de comumente atrelados a uma das pessoas do campo pesquisado, geravam agregações entre os membros do grupo. Tais cenas são interpretadas como sendo parte do que foi processado nos espaçostempos cotidianos vivenciados na formação, deixando ver maneiras coletivamente organizadas de atuar do/no grupo.

\section{AMBIÊNCIA CURRICULAR, MANEIRAS DE ESTAR-JUNTO E ACONTECIMENTOS CURRICULARES NOS COTIDIANOS FORMATIVOS}

O episódio a seguir nasceu com as descrições implicadas dos cotidianos coletivamente vivenciados ao longo do período de observação nos campos empíricos. Para fins de composição deste artigo, um dentre os oito episódios interpretativos que compuseram o texto final da pesquisa foi selecionado e discutido. Ao longo do episódio, mas, principalmente, depois dele, debato, ao lado dos seus praticantes, as questões levadas às cenas e suas implicações pedagógicas curriculares no ensino de Biologia. Tentando ampliar o debate, discuto também o modo como tais implicações segregam posicionamentos do que seja o fazer curricular no espaçotempo da escola, o contexto do aluno, a ciência escolar e a ciência de referência, entre outros temas. Ressalto, desde já, que não foi minha intenção e, talvez, nem seja compatível com as perspectivas filosóficas aqui adotadas, tentar esgotar todas as possibilidades de

\footnotetext{
${ }^{6}$ De acordo com Pimentel (2009) é através de um longo período de imersão no campo investigado que a experiência do estranhamento em relação ao que é senso comum e que induz os padrões culturais de um modo de vida acontece. Assim, o rompimento com o senso comum, compreendido em termos do que é consenso no campo investigado, produz condição para interpretação do seu objeto de estudo à luz de teorias e sistemas de análises produzidos pelas tradições de pensamento em que a pesquisa está situada.
} 
Atos de Pesquisa em Educação - ISSN 1809-0354

Blumenau - vol. 11, n. 2, p.590-610 ago./nov. 2016

DOI: http://dx.doi.org/10.7867/1809-0354.2016v11n2p590-610

discussão suscitadas pelo episódio. Trata-se de compreender que a história que construo neste trabalho já é, em si, uma construção perspectivada pelo lastro de referências entre as quais tenho caminhado na pesquisa em educação. Isto significa que este é apenas um dentre outros tantos modos possíveis de contá-la e debatê-la.

\section{Cenas e Máscaras do/no Cotidiano \\ Episódio | Transfigurações da força imaginária do conhecimento "atual" nas práticas pedagógicas curriculares}

Diário de campo, Faculdade de Educação, Salvador, 26/04/2011

- Clasmocitose? Não, não, não, não precisa falar sobre isso não, minha filha, é só mais um nome técnico para encher a cabeça deles... Retrucava a Professora Regente e Supervisora Escolar. Estudante 1.

- Tudo bem, e ligação peptídica, apresento a eles ou pode cortar também? Perguntava

- Ligação peptídica tem que falar que eu vou precisar na próxima unidade... Esclarecia a Professora Regente e Supervisora Escolar.

De modo evidente, o diálogo acima traduz o espírito da situação que se apresentava: um ar de querela entre o supostamente ultrapassado e simples, representados nas práticas curriculares do professor supervisor da escola, e o atual e complexo, representados nas práticas curriculares dos licenciandos em estágio. Um encontro conflituoso se instaurava: de um lado, práticas já enraizadas reclamavam sua atualidade e serventia nas composições curriculares de ensino de Biologia e, de outro lado, práticas e desejos irreprimíveis, ainda em via de formação, lutavam por compor também o mesmo espaço. Uma leitura rápida do episódio, aderindo cegamente aos valores apresentados, colocaria as constatações na esteira do progresso e da superação pelo atual: o velho está morto, o atual está vivo, é preciso ir em frente! $E$, talvez assumindo tal postura, não houvesse ruptura com o senso comum formado naquele grupo, não houvesse estranhamento desses valores já que, automaticamente, continuaria professando-os através deste trabalho. No entanto, com o desafio de deixar de lado a simples negação e superação do que existe em nome do novo e atual e, também, com a incumbência de compreender tais posicionamentos a partir dos seus próprios sentidos, sentia que esta querela poderia ser pensada em termos de uma futilidade ambientalmente necessária. Isto é, trata- 
Atos de Pesquisa em Educação - ISSN 1809-0354

Blumenau - vol. 11, n. 2, p.590-610 ago./nov. 2016

DOI: http://dx.doi.org/10.7867/1809-0354.2016v11n2p590-610

se de compreendê-la em seu próprio sentido e de modo aderido ao que foi formativo nos espaçostempos vividos. Trata-se, enfim, de epifanizar as práticas, realçando seus contornos, deixando ver o modo como tal futilidade surge, com força titânica, no imaginário coletivo dos licenciandos em estágio. Poderia dizer que, ao lado das perspectivas utilitaristas, que comumente poderiam ver tais futilidades como inúteis à imagem da educação ideal e de qualidade, o pensar estético põe em evidência outra maneira de delinear as maneiras de estar-junto em determinado grupo, indicando a conexão, o compartilhamento e a implicação com os ambientes formativos intensamente vividos e incorporados. Essa moda do atual, já que não responde a nenhuma utilidade objetiva, que venho chamando de força imaginária do "atual", representa, explicitamente, valores e crenças em torno dos quais as pessoas fundiamse num coro aparentemente uníssono. Trata-se de algo puramente estético e sem utilidade imediata que, contraditoriamente, fortalecia o corpo do campo empírico demonstrando sua organicidade:

Professor [referindo-se ao professor universitário], precisamos saber exatamente qual o poder de interferência do professor regente [referindo-se ao professor da escola onde realizava o estágio supervisionado] nas nossas aulas. Eles vão orientar a gente em que sentido? Porque a gente sai da universidade tentando inovar na escola e quando chega na sala de aula não podemos fazer o que queremos porque o professor regente, no meu caso professora, impede a gente de fazer algo novo, de levar o que a gente aprendeu de mais atual na universidade para os alunos. (ESTUDANTE 1, 2011)

Eu acho que nossa aula pode ficar muito tendenciada pelo que o professor regente quer [...]. Tem coisas que já estão ultrapassadas e a gente tem que continuar ensinando isso porque não podemos levar o conhecimento mais atual. A gente enfrenta uma resistência muito grande na escola, não podemos inovar nada. Biocel ${ }^{7}$, por exemplo, muda muito rápido e a gente já sabe de coisas mais novas que o professor regente não sabe, mas mesmo assim tem que ensinar tudo que está no livro didático e só. [...] Fora o que já faz parte do planejamento da escola, que a gente não tem direito de mudar nada. [...] $\mathrm{Na}$ primeira aula, por exemplo, a professora disse que fui superficial. $\mathrm{Na}$ última agora, disse que eu falei demais, dei informações desnecessárias, to me sentindo meio perdida. (ESTUDANTE 2, 2011)

Acho que essa angústia de estudante 2 é a mesma de todos nós. A gente se baseia nos livros didáticos, avalia a quantidade de informação que o livro traz para nivelar a nossa fala, mas algumas coisas vêm a nossa mente espontaneamente na aula e sai, e temos que trabalhar com aquilo. Tem essa espontaneidade, às vezes, que é vista como aprofundamento desnecessário, mas não foi planejado. (ESTUDANTE 3, 2011)

\footnotetext{
7 Termo comumente utilizado para se referir à disciplina Biologia Celular e Molecular cursada no segundo semestre do curso de Biologia tanto na licenciatura como no bacharelado.
} 
Atos de Pesquisa em Educação - ISSN 1809-0354

Blumenau - vol. 11, n. 2, p.590-610 ago./nov. 2016

DOI: http://dx.doi.org/10.7867/1809-0354.2016v11n2p590-610

quebra-cabeça estava posto! Confesso que nos primeiros momentos de imersão no campo e na condição de observador participante que havia vivido intensamente este percurso formativo e defendido, muitas vezes, os posicionamentos explicitados acima, ainda não conseguia compreender o quebra-cabeça posto através de tais defesas. Tais posicionamentos compõem a dimensão tácita (POLANYI, 1974) da aprendizagem no percurso formativo dos licenciandos, uma dimensão que, incorporada de modo acrítico através do treinamento científico intensamente cultivado e incorporado naquela comunidade, expressa valores e tradições das quais os aprendizes são imbuídos ao se lançarem no mundo da tradição científica ao qual estão filiados. Uma atmosfera englobante de redes de saberes e dizeres na qual são treinados e convidados a contribuir para. E é justamente nesse sentido que pode ser (re)visitado imanentemente, trazendo à luz os modos inconscientes e ainda pouco formalizados, posto em palavras, desta arte de fazer currículo governadas por esta tribo. Foi lendo o artigo abaixo - do qual trago apenas alguns trechos - publicado no Jornal da Ciência, enviado diariamente para os associados da Sociedade Brasileira para o Progresso da Ciência (SBPC) via email, que o despertar para esta tradição esteticamente formada veio à tona:

Entretanto, nem tudo está perdido e temos uma luz no horizonte, bastando para isso uma mudança de paradigma educacional. Sabemos o quanto é difícil a aceitação de um novo modelo ou paradigma, mas a realidade mostra que ou mudamos ou somos engolidos pela Esfinge tecnológica. Ao contrário da Matemática, que é uma ciência estática e que desde Pitágoras na Grécia em 490 a.C se mantém em seus teoremas, a Biologia é dinâmica e muda a cada segundo. Portanto, hoje os livros didáticos de Biologia estão na época de Watson e Crick, enquanto os cientistas discutem as aplicações da biologia sintética. Fica claro, que temos que adotar uma nova lógica na educação, onde o professor, como principal ator no processo fale a linguagem que o aluno entenda e que esteja motivado para escutar. [...] Hoje já temos professores de Biologia que reconhecem que "o aluno aprende muito mais quando o professor fala sua língua", comenta o professor Rubens Oda, coordenador da OBB. Temos vários exemplos na Internet de aulas de Biologia bastante fora do "convencional", que ensina, por exemplo, estrutura vegetal por meio de um vídeo acreditem, da "Lady Gaga"; ou mesmo uma aula sobre hormônios cantada em ritmo de "Funk", onde os alunos vibram e se envolvem totalmente no aprendizado. [...] Por que os alunos muitas vezes não são motivados pela Biologia? Infelizmente, a abordagem livresca de conteúdos quase sempre desatualizados, dificulta a aprendizagem e perdem a chance de mostrar como o ensino de ciências pode ser contextualizado e motivador. (JC e-mail 4275, de 08 de junho de 2011) 
Atos de Pesquisa em Educação - ISSN 1809-0354

Blumenau - vol. 11, n. 2, p.590-610 ago./nov. 2016

DOI: http://dx.doi.org/10.7867/1809-0354.2016v11n2p590-610

Contexto do aluno, conhecimento mais atual, abordagem livresca, aplicação do conhecimento no cotidiano, dificuldade de expressão, foram temas que apareciam constantemente no campo empírico gerando agrupamentos. Agrupamentos surgiam também quando era posto em debate a dificuldade na comunicação do conhecimento científico no espaço escolar, uma angústia compartilhada por todos os licenciandos frente às dificuldades postas no que tange à mobilização dos alunos durante as aulas; através das falas das pessoas pesquisadas, tinha a impressão que uma espécie de abismo de significados se instaurava entre as práticas de ensino e aprendizagem:

\footnotetext{
Minha aula foi sobre componentes membranosos. Acho que não consegui atingir o objetivo, pois faltou falar da membrana em procariotos. Fiquei nervosa com a presença da professora [referindo-se à professora universitária]. Em relação ao feedback, a professora regente [referindo-se à professora da escola] disse que aprofundei demais e trouxe muitas atualidades. Perguntei a ela se foi só porque falei da estrutura das membranas em arqueobactérias, em flip-flop e lipid-rafting e ela disse que não só isso, que era uma questão de linguagem, que to falando numa "linguagem" muito acadêmica. (ESTUDANTE 4, 2011)
}

Sentia cada vez mais que a hora de ruminar sobre essas constatações acerca dos campos empíricos pesquisados se aproximava! No entanto, o receio de como interpretar, teoricamente, esses achados sem incorrer numa abordagem puramente racionalista e alijante da dimensão sensível me angustiava, até mesmo por uma questão de formação. Era preciso pensar em uma forma que não negasse nem promovesse hierarquizações entre as formas de conhecimento.

O episódio acima traz depoimentos que retratam manifestações estéticas das redes de saberes, dizeres e fazeres cotidianamente com-partilhadas e estruturantes das tessituras e significações curriculares, no momento do estágio supervisionado. Trata-se de cenas registradas que convidam a pensar sobre escola, currículo, saberes, formação e práticas pedagógicas curriculares de Biologia. Neste episódio em particular, debates sobre contexto do aluno, conhecimento atual e dificuldades de comunicação da ciência tomaram a cena. Tais debates colocaram em evidência desejos de significação curricular (CARVALHO, 2001) daquela comunidade por meio de conhecimentos atualizados como forma de avançar sobre as práticas supostamente tradicionais. Problematizo aqui, especificamente, duas das apostas mais debatidas: (i) a aposta na recorrência ao contexto do aluno em uma linguagem 
Atos de Pesquisa em Educação - ISSN 1809-0354

Blumenau - vol. 11, n. 2, p.590-610 ago./nov. 2016

DOI: http://dx.doi.org/10.7867/1809-0354.2016v11n2p590-610

científica atual como forma de significar o currículo e facilitar a comunicação da ciência; (ii) a aposta no conhecimento atualizado como supostamente mais significativo: uma querela entre ensinar o que está estabelecido - entendido como o "tradicional" - e o que é recente em termos de descoberta da ciência - entendido como o "atual". Levanto algumas questões para iniciar a discussão: (i) em que medida é possível, através de aulas, capturar plenamente, isto é, saturar (DERRIDA, 1991) o contexto do aluno e determiná-lo de uma vez por todas? (ii) Não sendo isto possível, como pensar em uma aula plena e previamente contextualizada, capaz de comunicar os mesmos e atuais conteúdos a todos da mesma forma? (iii) Em que medida correr nos calcanhares da ciência pode, de fato, contribuir no preenchimento do abismo de sentidos e significados entre alunos, professor e conteúdos conceituais que se instaura nas aulas de Biologia? (iv) De que forma a tessitura dos acontecimentos curriculares cotidianos via incorporação constante de produtos atuais no currículo pode contribuir na manutenção de uma formação em ciências de qualidade, como é defendido de modo enfático? (v) De que forma esse conhecimento atual aparece nas práticas pedagógicas? (vi) É conveniente sustentar que o tratamento e a construção do conhecimento no espaço escolar ande pari passu aos avanços de sua disciplina de referência? (vii) À necessidade de humanizar a ciência escolar como forma de mobilização do interesse dos alunos (MATTHEWS, 1995), corresponde a defesa da tessitura dos acontecimentos curriculares cotidianos com base em práticas pedagógicas de ensino de Biologia jornalísticas - currículo jornalístico?

Inicio a discussão destas questões problematizando a ideia de que a recorrência ao contexto do aluno e sua suposta tradução em uma linguagem científica acadêmica permite plena comunicação da ciência na escola e mobilização de interesse dos alunos. Apoiado em Derrida (1991), tenho defendido que a tentativa de querer contextualizar absolutamente, para fins de comunicação plena e direta, uma aula pode ser impossível. Com base nele, é possível afirmar que um contexto, por mais rigorosamente mapeado que possa vir a ser, nunca é plenamente determinável, captável, isto é, que sua determinação nunca está passível de saturação. Nesse sentido, defendo que a tentativa dos licenciandos em querer contextualizar plenamente a aula, por meio de recorrência a problemas cotidianos reformulados em linguagem científica atual, pode ser uma tarefa importante nas tessituras curriculares, 
Atos de Pesquisa em Educação - ISSN 1809-0354

Blumenau - vol. 11, n. 2, p.590-610 ago./nov. 2016

DOI: http://dx.doi.org/10.7867/1809-0354.2016v11n2p590-610

mas nunca plenamente atingível. Essas tentativas de contextualização e de dificuldades de comunicação podem ser compreendidas nas frustrações e queixas de dificuldades de comunicação coletivamente compartilhadas durante o estágio supervisionado. Trata-se de queixas e frustrações fundadas em uma ideia de aula e de currículo como uma comunicação direta e plena que, a meu ver, pode ser impossível, mesmo pela contextualização exaustiva, em linguagem científica, das questões que permeiam os cotidianos dos alunos. Isto não significa que devemos abandonar as práticas de contextualização da aula, significa apenas a problematização das tentativas exaustivas de contextualização pautadas nos produtos científico-acadêmicos atuais. A meu ver, uma tentativa fundada em uma concepção de currículo escolar continuísta (LOPES; MACEDO 2011) com a tradição acadêmica da própria Biologia que, também, precisa ser problematizada, ainda que nos pareça óbvio vinculá-las de um ponto de vista identitário.

Passando à problematização da aposta no conhecimento atual como mais significativo nas tessituras curriculares de Biologia e na defesa do currículo jornalístico, a princípio, pode parecer difícil e conservador sustentar um possível desacordo com tal posição. No entanto, penso que esta é uma discussão que não pode passar ao largo das questões acerca das diferenças entre a dinâmica espaçotemporal de produção de conhecimento escolar e a dinâmica espaçotemporal de produção de conhecimento na comunidade científica. Soma-se a esta discussão duas outras: a visão de ciência escolar como mera simplificação e sumarização dos produtos da ciência e a problematização da relação especular entre ciência escolar e ciência da comunidade científica. Se, por um lado, o tratamento do conhecimento biológico nas escolas já carece de princípios organizadores e unificadores, contribuindo na manutenção do tratamento fragmentário do conhecimento dessa disciplina no espaço escolar (MARANDINO; SELLES; FERREIRA, 2009), por outro lado, a defesa do conhecimento atual deixa uma nova dúvida: (viii) esta forma de significação curricular pode vir a ser mais uma produtora de tratamentos fragmentários ao defender a permanente atualização na divulgação dos produtos da ciência? (ix) De que forma essas tessituras e apostas no conhecimento atual poderiam estar conectadas à ambiência proporcionada pelos espaçostempos formativos dos 
Atos de Pesquisa em Educação - ISSN 1809-0354

Blumenau - vol. 11, n. 2, p.590-610 ago./nov. 2016

DOI: http://dx.doi.org/10.7867/1809-0354.2016v11n2p590-610

licenciandos e futuros professores, vividos prioritariamente em meio à educação científica?

\begin{abstract}
A educação científica tal como hoje a conhecemos tem precisamente esse objetivo. Simplifica a "ciência" pela simplificação de seus participantes: primeiro, define-se um campo de pesquisa. Esse campo é separado do restante da história (a física, por exemplo, é separada da metafísica e da teologia) e recebe uma "lógica" própria. Um treinamento completo em tal lógica condiciona aqueles que trabalham nesse campo; torna suas ações mais uniformes e também congela grandes porções do processo histórico. Fatos "estáveis" surgem e mantêm-se a despeito das vicissitudes da história. [...] Sua imaginação é restringida, e até sua linguagem deixa de ser própria. Isso se reflete na natureza dos "fatos" científicos, experienciados como independentes de opinião, crença e formação cultural. (FEYERABEND, 2007, p.34)
\end{abstract}

Grande parte da imagem que cientistas e leigos têm da atividade científica criadora provém de uma fonte autorizada que disfarça sistematicamente a existência e o significado das revoluções científicas. [...] Quando falo de autoridade, penso sobretudo nos principais manuais científicos, juntamente com os textos de divulgação e obras filosóficas moldadas naqueles. Referemse a um corpo já articulado de problemas, dados e teorias, e muito frequentemente ao conjunto particular de paradigmas aceitos pela comunidade científica na época em que foram escritos. [...] As obras de divulgação tentam descrever essas mesmas aplicações numa linguagem mais próxima da utilizada na vida cotidiana. [...] Todas elas registram o resultado estável das revoluções passadas e desse modo põe em evidência as bases da tradição corrente da ciência normal. [...] Deste modo, os manuais começam truncando a compreensão dos cientistas a respeito da história de sua própria disciplina e em seguida fornecem um substituto para aquilo que eliminaram. [...] Não é de admirar que, ao ser reescrita [nos manuais], a ciência apareça, mais uma vez, como sendo basicamente cumulativa. (KUHN, 2009, p.175-178)

A meu ver, uma primeira constatação se torna evidente: o modelo " $3+1$ " de formação de professores, notadamente pautado na racionalidade técno-científica manualística da ciência, tem contribuído na manutenção de conflitos estéticos, expressos na dificuldade dos licenciandos no que tange à compreensão dos discursos pedagógicos como estruturantes, anteriores à entrada na lógica do conteúdo disciplinar, que marcam as significações nos currículos escolares. Estas constatações põem em xeque a simples solução de diminuição da quantidade de conteúdos bem como dos conteúdos atualizados como forma de significar a educação científica nos espaços escolares. Defendo que pode ser conveniente refletir, ao lado das supostas soluções quantitativas de adições/subtrações mecânicas de conteúdos atualizados nos materiais didáticos, o quanto o próprio nicho proporcionado pelas redes da ambiência nos espaçostempos cotidianos formativos pode ser determinante, em 
Atos de Pesquisa em Educação - ISSN 1809-0354

Blumenau - vol. 11, n. 2, p.590-610 ago./nov. 2016

DOI: http://dx.doi.org/10.7867/1809-0354.2016v11n2p590-610

alguma medida, dos modos de estruturação das práticas de ensino daqueles que por estes ambientes enveredam. $O$ desejo de significação curricular expresso por esta comunidade, através de divulgação de conhecimentos atualizados, pode, portanto, ratificar a visão fragmentária e simplista que, cotidianamente, tem minado a visão unificada e os princípios integradores estruturantes da Biologia na escola. É um desejo/forma de significação que deixa ver marcas de formação prioritariamente técnica, através de manuais historicamente truncados que sumarizam a história da ciência e da Biologia e as tornam ciências aproblemáticas e lineares.

Subjacente à esta maneira de estar-junto nas tessituras curriculares via conhecimentos atualizados, está a problematização da relação especular entre ciência escolar e ciência praticada na comunidade científica. A partir das perspectivas aqui assumidas, é possível interrogar a lógica que permanece caracterizando a ciência escolar como produtora de imagens deformadas da natureza da ciência em relação à visão de ciência praticada na comunidade científica. Trata-se de compreender, seguindo a lógica das constatações acima, que as temporalidades características das tessituras curriculares nos cotidianos escolares emergem em meio às dinâmicas espaciais e temporais próprias da escola, que não perseguem necessariamente as virtudes epistêmicas para fins de instituição e legitimação. Defendo que são tessituras e significações curriculares engendradas em meio a acontecimentos prático-simbólicos singulares. Apoiado em Lopes e Macedo (2011) e nos estudos do/no cotidiano (ALVES, 2001; 2003; OLIVEIRA, 2007), tenho avançado na defesa das disciplinas escolares como construções discursivas próprias do processo de escolarização. Não devem, portanto, ser estruturadas e entendidas como uma simplificação atualizada dos conhecimentos de nível superior. É justamente nesse sentido que problematizo as significações curriculares pautadas na ideia de conhecimento atual que, a meu ver, estão ligadas a uma compreensão da escola pela ideologia do "consumo-receptáculo" (CERTEAU, 2009), isto é, como local de repetição mecânica de conhecimentos produzidos em outros contextos. Tal leitura da escola está fundada num debate no qual "são postos em lados opostos os sujeitos que dominam os saberes considerados legítimos [os saberes atuais] e os sujeitos que dominam os saberes deslegitimados [os saberes descontextualizados]." (LOPES; MACEDO, 2001, p. 91). Opõe-se, de modo simplista e maniqueísta, os que 
Atos de Pesquisa em Educação - ISSN 1809-0354

Blumenau - vol. 11, n. 2, p.590-610 ago./nov. 2016

DOI: http://dx.doi.org/10.7867/1809-0354.2016v11n2p590-610

supostamente sabem selecionar o melhor conteúdo para o currículo e os conservadores que se acomodam em práticas desatualizadas.

Seguindo linha de argumentação distinta, as perspectivas com as quais tenho operado permitem questionar radicalmente a separação entre produção e implementação do conhecimento, bem como a condenação da escola e seus praticantes à mera reprodução de produtos culturais. Defendo que é preciso levantarse contra tais analises, pois elas destituem os praticantes escolares de poder criativo e tentam fixar a identidade da escola como lócus de conservação de conhecimentos descontextualizados e desatualizados, com vistas a hegemonizar uma dada significação de currículo - o currículo jornalístico. Trata-se, por fim, de levantar-se contra as tentativas de minar com as demandas da diferença e instaurar, nas práticas e em seus praticantes, uma busca compulsiva por um espaço no território de identidades de práticas cientificamente reconhecíveis e atuais; isto é, práticas que tentam se aproximar cada vez mais de uma imagem cientificamente representativa. Tal defesa permite, portanto, avançar na "reafirmação política da dimensão poética do cotidiano, seu aspecto inventivo e criativo" (PIMENTEL-JÚNIOR, 2015), permitindo pensar nos espaçostempos escolares em sua diferença.

Finalizo considerando que essas constatações descrevem como os espaçotempos cotidianos e a força estética da ambiência modalizam, condicionam não determinam - maneiras de estar-junto e são estruturantes nas significações e tessituras dos acontecimentos curriculares nas práticas de ensino de Biologia. Maneiras de estar-junto que, ao passo que transcendiam cada indivíduo do grupo, ligava-os a uma imanência local: uma forma orgânica de compreender as pessoas em suas maneiras de existir bem como a diversidade de máscaras que segregam como (in)formantes de um ambiente curricular. Sobretudo, constatações que nos convidam a pensar nas implicações pedagógicas dos valores propagados nos espaçostempos de formação de professores.

\section{CLÍVIO PIMENTEL JUNIOR}

Licenciado em Ciências Biológicas (IBio/UFBA). Mestre em Educação (FACED/UFBA). Professor Substituto no Departamento de Educação II, Faculdade de Educação, Universidade Federal da Bahia. Membro do Grupo de Pesquisa Formação em Exercício de Professores (FEP/FACED/UFBA). 
Atos de Pesquisa em Educação - ISSN 1809-0354

Blumenau - vol. 11, n. 2, p.590-610 ago./nov. 2016

DOI: http://dx.doi.org/10.7867/1809-0354.2016v11n2p590-610

\section{REFERÊNCIAS}

ALVES, N. Decifrando o pergaminho: o cotidiano das escolas nas lógicas das redes cotidianas. In: OLIVEIRA, Inês Barbosa de; ALVES, Nilda (Orgs.). Pesquisa no/do cotidiano das escolas: sobre redes de saberes. Rio de Janeiro: DP\&A, 2001. p.1338.

ALVES, N. Cultura e cotidiano escolar. Revista Brasileira de Educação. Rio de janeiro, no 23, p.62-74 maio/jun/jul/ago, 2003.

CARVALHO, Maria Inez da Silva de Souza. Uma viagem pelos espaços educacionais do município de Santo Antônio de Jesus - possibilidades, atualizações, transituações. 2001. 180p. Tese (Doutorado) - Faculdade de Educação, Universidade Federal da Bahia, Salvador.

CERTEAU, M. A Invenção do Cotidiano: 1. Artes de fazer. Petrópolis: Vozes, 2009.

DERRIDA, Jacques. Margens da Filosofia. Campinas: Papirus, 1991.

ERICKSON, Frederick. Qualitative Methods in Research on Teaching. Ocasional paper no81. Michigan State University, East Lansing. Institute for Research on Teaching, 1985, 147p.

ESTUDANTE 1. Depoimento oral. Diário de campo, Salvador, 26 de abril de 2011.

ESTUDANTE 2. Depoimento oral. Diário de campo, Salvador, 26 de abril de 2011.

ESTUDANTE 3. Depoimento oral. Diário de campo, Salvador, 05 de maio de 2011.

ESTUDANTE 4. Depoimento oral. Diário de campo, Salvador, 09 de junho de 2011.

FEYERABEND, Paul. Contra o Método. São Paulo: Editora UNESP, 2007.

FOUCAULT, M. Polêmica, política e problematizações. In: FOUCAULT, M. Ética, sexualidade, política. (Col.) Ditos e Escritos V. Rio de Janeiro: Forense Universitária, 2006.

GIARD, Luce. Artes de Nutrir. In: CERTEAU, Michel de.; GIARD, Luce.; MAYOL, Pierre. A invenção do cotidiano: 2. Morar, Cozinhar. 9ae ed. Petrópolis: Vozes, 2009. KUHN, T. A estrutura das revoluções científicas. São Paulo: Perspectiva, 2009.

LOPES, A. C; MACEDO, E. Teorias de Currículo. São Paulo: Cortez, 2011. MAFFESOLI, Michel. No fundo das aparências. Petrópolis: Vozes, 1996, 350p.

LOPES, A. C; MACEDO, E. A transfiguração do político: a tribalização do mundo. (Trad.) Juremir Machado da Silva. $3^{\underline{a}}$ ed. Porto Alegre: Sulina, 2005, 230p. 
Atos de Pesquisa em Educação - ISSN 1809-0354

Blumenau - vol. 11, n. 2, p.590-610 ago./nov. 2016

DOI: http://dx.doi.org/10.7867/1809-0354.2016v11n2p590-610

LOPES, A. C; MACEDO, E. Elogio da razão sensível. 4ed. Pretópolis: Vozes, 2008. $207 p$.

MARANDINO, Martha; SELLES, Sandra; FERREIRA, Marcia. Ensino de Biologia: histórias e práticas em diferentes espaços educativos. São Paulo: Cortez, 2009.

MATTHEWS, M. R. História, filosofia e ensino de ciências: a tendência atual de reaproximação. Caderno Catarinense de Ensino de Física, Florianópolis, v.12, n.3, p.164-214, 1995.

OLIVEIRA, Inês Barbosa de; ALVES, Nilda (Orgs.). Pesquisa no/do cotidiano das escolas: sobre redes de saberes. Rio de Janeiro: DP\&A, 2001.

OLIVEIRA, Inês Barbosa de. Certeau e as artes de fazer: as noções de uso, tática e trajetória na pesquisa em educação. In: OLIVEIRA, Inês Barbosa de; ALVES, Nilda (Orgs.). Pesquisa no/do cotidiano das escolas: sobre redes de saberes. Rio de Janeiro: DP\&A, 2001. p.39-54

OLIVEIRA, Inês Barbosa de; ALVES, Nilda. A pesquisa e a criação de conhecimentos na pós-graduação em educação no Brasil: conversas com Maria Célia Moraes e Acácia Kuenzer. Educação e Sociedade, Campinas, v. 27, n. 95, p.577-599, mai/ago. 2006.

OLIVEIRA, Inês Barbosa de. Aprendendo nos/dos/com os cotidianos a ver/ler/ouvir/sentir o mundo. Educação e Sociedade, Campinas, v. 28, n. 98, p. 4772, jan./abr. 2007.

PIMENTEL, Álamo. Considerações sobre a autoridade e o rigor nas etnografias da educação. In: MACEDO, R. S. Um rigor outro sobre a qualidade na pesquisa qualitativa: educação e ciências humanas. Salvador: EDUFBA, 2009. 174p.

PIMENTEL-JÚNIOR, Clívio. A Invenção Cotidiana da Ciência Escolar: sobre rede de saberes e maneiras de instituir práticas pedagógicascurriculares. Revista Teias. Rio de Janeiro, v. 16, n. 42, p. 163-176, jul/set, 2015.

POLANYI, Michael. Personal Knowledge: towards a post-critical philosophy. The University of Chicago Press. 1974.

SANTOS, Boaventura de Sousa. Renovar a teoria crítica e reinventar a emancipação social. São Paulo: Boitempo, 2007.

VATTIMO, Gianni. O fim da Modernidade: niilismo e hermenêutica na cultura pósmoderna. (Trad.) Eduardo Brandão. 2ª̊ed. São Paulo: Martins Fontes, 2007. 